\title{
Contents of \\ THE AMERICAN JOURNAL OF PSYCHIATRY
}

Volume 147, Number 9

September 1990

\author{
Presidential Papers: 1990 \\ 1113 Presidential address: defending humanistic values. Herbert Pardes \\ 1120 Response to the Presidential address: our children: our future. Elissa P. Benedek \\ 1126 Herbert Pardes, MD, one hundred eighteenth President, 1989-1990. H. Keith H. Brodie \\ Special Article \\ 1128 Family functioning and major depression: an overview. Gabor I. Keitner and Ivan W. Miller
}

Regular Articles

1138 Continuous versus targeted medication in schizophrenic outpatients: outcome results. William T. Carpenter, Jr, Thomas E. Hanlon, Douglas W. Heinrichs, Ann T. Summerfelt, Brian Kirkpatrick, Jerome Levine and Robert $W$. Buchanan

1149 Neuroleptic malignant syndrome in 12 of 9792 Chinese inpatients exposed to neuroleptics: a prospective study. Ming Zhen Deng, Guo Qiang Chen and Michael R. Phillips

1156 Factors in the development of severe forms of tardive dyskinesia. Ramzy Yassa, Neelakanta P. V. Nair, Hani Iskandar and George Schwartz

1164 Cocaine abuse among schizophrenic patients. Kathleen Brady, Raymond Anton, James C. Ballenger, R. Bruce Lydiard, Bryon Adinoff and Jean Selander

1168 Maladaptive denial of physical illness: a proposal for DSM-IV. David H. Strauss, Robert L. Spitzer and Philip R. Muskin

1173 Variability in the application of contemporary diagnostic criteria: endogenous depression as an example. Mark Zimmerman, William H. Coryell and Donald W. Black

1180 Regional variation in patterns of inpatient psychiatric care. Roberi Rosenheck and Boris Astrachan

1184 Relation of clinical variables to dissociative phenomena in eating disorders. Mark A. Demitrack. Frank W. Putnam, Timothy D. Brewerton, Harry A. Brandt and Philip W. Gold

1189 Time-related predictors of suicide in major affective disorder. Jan Fawcett, William A. Scheftner, Louis Fogg, David C. Clark, Michael A. Young, Don Hedeker and Robert Gibbons

1194 Life events and the course of bipolar disorder. Aimee Ellicott, Constance Hammen, Michael Gitlin, Gary Brown and Kay Jamison

1199 Comorbidity of major depression and anxiety disorders in twin pairs. Svenn Torgersen

1203 Amoxapine versus amitriptyline combined with perphenazine in the treatment of psychotic depression. Raymond F. Anton, Jr and Earl A. Burch, Jr

1209 A controlled trial of fluvoxamine in obsessive-compulsive disorder: implications for a serotonergic theory. Michael A. Jenike, Steven Hyman, Lee Baer, Amy Holland, William E. Minichiello, Lynn Buttolph, Paul Summergrad, Ralph Seymour and Joseph Ricciardi

1216 Alexithymic features in relation to the dexamethasone suppression test in a Finnish population sample. Tomi Lindholm, Ville Lehtinen, Markku T. Hyyppä and Pauli Punkka

Commentary

1220 The coming crisis in funding child psychiatry training. Robert S. McKelvey

\section{Clinical and research reports}

1225 CSF 5-HIAA and HVA concentrations in elderly depressed patients who attempted suicide. J. Sidney Jones, Barbara Stanley, J. John Mann, Allen J. Frances, Jeannine R. Guido, Lil Traskman-Bendz, Ronald Winchel, Richard P. Brown and Michael Stanley

1228 A preliminary investigation of alexithymia in men with psychoactive substance dependence. Graeme $J$. Taylor. James D. A. Parker and R. Michael Bagby

1231 Prevalence of neuroleptic-induced dystonia in mania and schizophrenia. Gary J. Remington, George Voineskos, Bruce Pollock, Ken Reed and Kathryn Coulter

1234 Positive and negative symptoms and social competence in adolescents at risk for schizophrenia and affective disorder. Robert H. Dworkin, Susan R. Green, Nancy E. Small, Matthew L. Warner, Barbara A. Cornblatt and L. Erlenmeyer-Kimling 